\title{
Effects of omega-3 polyunsaturated fatty acid supplementation on parameters of glycaemic control in people with type 1 diabetes: a double-blind, randomised, placebo-controlled trial
}

\author{
L.L. O’Mahoney ${ }^{1}$, A.M. Alobaid ${ }^{2}$, R.A. Ajjan ${ }^{3}$, K.M. Birch ${ }^{4}$, N.M. Orsi ${ }^{5}$, G. Mappa ${ }^{5}$, \\ M. Holmes ${ }^{2}$, P. Ho ${ }^{2}$, A. Stavropoulos-Kalinoglou ${ }^{1}$, O.J. Price ${ }^{1}$ and M.D. Campbell ${ }^{2}$ \\ ${ }^{1}$ Carnegie School of Sport, Leeds Beckett University, Leeds, UK, \\ ${ }^{2}$ School of Food Science a Nutrition, University of Leeds, Leeds, UK, \\ ${ }^{3}$ School of Medicine, University of Leeds, Leeds, UK, \\ ${ }^{4}$ School of Biomedical Sciences, University of Leeds, Leeds, UK and \\ ${ }^{5}$ Leeds Institute of Cancer \& Pathology, St James's University Hospital, Leeds, UK
}

The effect of omega-3 polyunsaturated fatty acid (n-3 PUFA) supplementation on glycaemic control in T1D remains unclear ${ }^{(1)}$. Additionally, the effects of n-3 PUFA on postprandial glucose control in T1D are unknown. Here, we report the effect of 6-month supplementation with a daily high-dose-bolus of n-3 PUFA on parameters of glycaemic control in people with T1D.

For this double-blind, randomized, placebo-controlled trial, individuals with T1D ( $\mathrm{n}=18$; males: 14; $35 \pm 15$ years; BMI: $26.6 \pm$ $5.2 \mathrm{~kg} / \mathrm{m}^{2}$; glycated haemoglobin $\left.\left(\mathrm{HbA}_{1 \mathrm{c}}\right): 59 \pm 13 \mathrm{mmol} / \mathrm{mol}^{-1}[7.5 \pm 3.3 \%]\right)$, were randomly allocated in a 1:1 ratio to receive either $3.3 \mathrm{~g} /$ day of encapsulated n-3 PUFA or placebo (PLA) consisting of an encapsulated dose of $3.0 \mathrm{~g} /$ day corn oil for 6-months. Venous blood samples were obtained at baseline, and 6-months, to determine $\mathrm{HbA}_{1 \mathrm{c}}$, fasting plasma glucose (FPG), and postprandial glucose responses (PPGR) to a standardised mixed-meal tolerance test assessed by area under the curve over a 4-hour period. Fatty acids were measured in erythrocyte membranes by gas chromatography with n-3 PUFA index (O3I) calculated as eicosapentaenoic acid plus docosahexaenoic acid. Paired-samples $t$ tests were used to compare intragroup mean differences with statistical significance set at $p \leq 0.05$. Data are presented as mean $\pm \mathrm{SD}$.

In the n-3 PUFA group, baseline O3I increased from $4.97 \pm 0.98 \%$ to $8.24 \pm 1.52 \%$ after 6-months ( $<<0.001$ ). O3I in PLA did not change (baseline: $4.31 \pm 1.22 \%$ vs. 6-months: $4.58 \pm 1.59 \%, \mathrm{p}=0.256$ ). In the $\mathrm{n}-3$ PUFA group, the mean difference between baseline and 6-months for $\mathrm{HbA}_{\mathrm{lc}}\left(-3.89 \pm 6.05 \mathrm{mmol} / \mathrm{mol}^{-1} ; \mathrm{p}=0.090\right)$, FPG $\left(-1.04 \pm 2.82 \mathrm{mmol} / \mathrm{L}^{-1} ; \mathrm{p}=0.301\right)$, and PPGR $(-607.03 \pm 2014.63$ $\left.\mathrm{mmol} / \mathrm{L}^{-1} / \mathrm{min}^{-1} ; \mathrm{p}=0.392\right)$ did not significantly differ. Similar findings were observed in the PLA group; $\operatorname{HbA}_{1 \mathrm{c}}(\mathrm{p}=0.208), \mathrm{FPG}(\mathrm{p}=$ $0.624)$, and PPGR $(\mathrm{p}=0.966)$. Overall, no safety issues arose during administration of $n-3$ PUFA or PLA.

Supplementation with a daily high-dose-bolus of n-3 PUFA for 6-months did not modulate $\mathrm{HbA}_{1 \mathrm{c}}$, FPG, or PPGR to a mixedmeal tolerance test in people with T1D. These findings do not support the use of n-3 PUFA supplementation as an adjunct therapy in the management of T1D.

1. De Caterina R, Madonna R, Bertolotto A et al. (2007) Diabetes Care 30, 1012-1026. 